\title{
CONHECIMENTO CIENTÍFICO, SEU ENSINO E APRENDIZAGEM: ATUALIDADE DO CONSTRUTIVISMO
}

\section{Scientific knowledge, its teaching and learning: constructivism present}

\author{
Gloria Regina Pessôa Campello Queiroz ${ }^{1}$ \\ Maria da Conceição Almeida Barbosa-Lima²
}

\begin{abstract}
Resumo: O presente artigo parte de uma ilustração acerca da etimologia da palavra construtivismo semear coletivamente - para, em seguida, reunir sementes a serem disponibilizadas aos alunos durante os cursos formação de professores de Física. Entre elas estão argumentos a favor de uma versão sustentável para o Construtivismo, reconhecendo críticas, de origem epistemológica, psicológica ou mesmo pedagógica, a aspectos particulares de versões que têm circulado entre pesquisadores da área de pesquisa em educação em ciências nos últimos anos. Com o compromisso de não nos limitarmos às críticas e diante da complexidade dos sistemas educacionais nos quais o debate sobre o Construtivismo é travado, sua versão pedagógica proposta neste trabalho integra uma visão de realidade mais próxima à aceitável pela comunidade de pesquisadores e professores de Física e ao valioso trabalho de criação de conhecimento científico na escola, que a comunidade de pesquisadores em ensino de Física vem realizando há mais de duas décadas no Brasil.
\end{abstract}

Palavras-chave: Construtivismo. Complexidade. Formação inicial de professores.

\begin{abstract}
The present article comes from an illustration of the etymology of the word constructivism - to sow together - and then gather the seeds that will be put at the pupils disposal throughout the courses for the development of Physics teachers. Among them there are arguments in favor of a sustainable version of Constructivism, recognizing the critics of epistemological, psychological or even pedagogical origin, to a few aspects of versions that have been circulated by researchers of education in science, in the last years. With the commitment of not being limited to criticism and in light of the complexity of educational systems about which the debate about Constructivism takes place, the pedagogical version proposed in this work integrates a vision of reality closer to that acceptable by the community of researchers and professors of Physics. There is valuable work in constructivist teaching of scientific knowledge that the community of researchers in education of Physics has carried out for more than two decades in Brazil as well as in other countries.
\end{abstract}

Key words: Constructivism. Complexity. Preliminary development of professors.

\footnotetext{
${ }^{1}$ Doutora em Educação; Departamento de Física Aplicada e Termodinâmica, Instituto de Física Armando Dias Tavares, Universidade do Estado do Rio de Janeiro (UERJ). Rio de Janeiro, RJ. < gloria@uerj.br>

${ }^{2}$ Doutora em Educação; Departamento de Física Aplicada e Termodinâmica, Instituto de Física Armando Dias Tavares, Universidade do Estado do Rio de Janeiro (UERJ). Rio de Janeiro. RJ.<mcablima@uol.com.br>
}

${ }^{1}$ Rua São Francisco Xavier, 524, $3^{\circ}$ andar, sala 3028, bloco B

Maracanã - Rio de Janeiro, RJ

$20.550-900$ 


\section{Introdução}

Por termos tido nossa formação inicial na área de Física e atualmente ministrarmos aulas na Universidade, especialmente na Licenciatura em Física, nos especializamos na área de pesquisa "Educação em Ciências", procurando realizar essa tarefa de formação de professores em ressonância com os consensos estabelecidos com nossos pares, pesquisadores e professores, que participam de uma comunidade que se fortalece a cada ano.

No entanto, por vezes, nos deparamos com sentimentos de saudade da época em que se tinha a ilusão de viver num mundo preciso, onde se acreditava que as proposições teóricas eram obtidas com base em fatos e dados que conduziam a leis expressas em equações matemáticas, que podiam ser comprovadas por meio de experiências bem controladas. Assim éramos levados a "certezas" respeitáveis, chegando-se a pensar em poder reduzir todas as ciências, inclusive as sociais, a uma metodologia que garantisse resultados verdadeiros.

Cientes dos limites da precisão determinística e da verdade na construção do próprio conhecimento em Física, e adotando uma postura de permanente crítica e reflexão sobre as teorias no campo da educação, repelimos, no entanto, as tentativas de "demolições" de alguns construtos teóricos que nos são caros e que estiveram presentes em nossas vidas em momentos pedagógicos ricos, durante os quais mediamos aprendizagens de indiscutível significação para professores em formação inicial ou continuada e, mesmo, para alunos da escola básica.

Uma "demolição" desse tipo é a que se vem presenciando com o Construtivismo, enfoque teórico que nos tem servido de suporte, para a maioria dos trabalhos realizados no âmbito da Didática das Ciências. Em contraste a isso, está a filiação indiscriminada de muitos ao Construtivismo, sem maiores esclarecimentos sobre a base teórica usada, entre as muitas que podem ser consideradas sob a denominação de construtivistas, desde que se encaixem em uma definição de aprendizagem de sentido amplo como a de Gilbert et al. (2000, p. 3): "o uso de idéias existentes para construir o significado de experiências novas ao mesmo tempo em que usa experiência adquirida para produzir novas idéias." ${ }^{3}$

Há alguns anos, Mortimer (2000) já assinalava a preocupação com o panteísmo construtivista ao afirmar que o Construtivismo se tornou um rótulo capaz de cobrir um grande número de visões diferentes, sendo algumas até mesmo inconsistentes. Porém, ao mesmo tempo, reconhecia que as pesquisas sobre as concepções dos alunos - quanto aos mais diversos conceitos científicos - alternativas à ciência, dominaram por muito tempo a área de Educação em Ciências e Matemática, e fortaleceram uma visão de ensino-aprendizagem que pode ser resumida em dois pontos, trazendo o mesmo tom da definição de Gilbert et al. (2000):

a aprendizagem se dá através do ativo envolvimento do aprendiz na construção do conhecimento; as idéias prévias dos estudantes desempenham um papel fundamental no processo de aprendizagem, já que essa só é possível a partir do que o aluno já conhece. (MORTIMER, 2000, p. 36)

\footnotetext{
${ }^{3}$ Tal utilização de algum aspecto especificamente relevante do conhecimento prévio do indivíduo para a construção de significados nos remete à história dos estudos cognitivistas sobre aprendizagem e, nela, ao conceito central da teoria de Ausubel (1968): aprendizagem significativa.
} 
Conhecimento científico, seu ensino e aprendizagem...

Invocando consensos contemporâneos da filosofia da ciência, entre os quais aquele que acredita que, no desenvolvimento da ciência, observações e experimentos desempenham o papel de argumentos críticos (OLIVA, 2003), o presente artigo pretende reunir idéias a favor de uma versão sustentável para o Construtivismo, identificando críticas, de origem epistemológica, psicológica ou mesmo pedagógica, a aspectos de outras versões veiculadas na pesquisa educacional. Nosso saber da experiência nos incita a fazer isto por acreditarmos que esse enfoque teórico se tornou orientador para muitas pesquisas, conseguindo reunir valores, teorias e modelos (de ensino-aprendizagem) respeitados por uma comunidade de especialistas em Educação, que os tomaram como base teórica para a resolução de uma série de problemas/dilemas da prática no campo da formação de educadores de Ciências.

Assim como acontece reconhecidamente na ciência, nossas corroborações requerem capacidade de argumentar. Tendo clareza da inconveniência de qualquer reducionismo constructivista (MARTÍ, 1996; POZO, 1996), procuraremos contribuir para evitar que a generalização das críticas desqualifique as tantas contribuições pedagógicas que o movimento construtivista propiciou, trazendo a perspectiva da complexidade do sistema humano de aprendizagem como uma possibilidade de articulação contemporânea do construtivismo.

Os alunos dos cursos de Licenciatura em Ciências, nas suas diferentes especialidades, desenvolvem suas concepções de ensino-aprendizagem tendo, como exemplo, a prática de seus próprios professores que, na maioria das vezes, os levam a ensinar da mesma forma expositiva como foram ensinados, dando continuidade a uma prática pedagógica afastada de uma reflexão crítica apoiada nas pesquisas da área educacional e, conseqüentemente, das opções construtivistas que podem provocar mudanças pedagógicas nesses estudantes.

A discussão sobre a estrutura dos currículos de licenciatura, realizada nas universidades cujos cursos de formação de professores possuem influência da pesquisa em Educação em Ciências, tem estabelecido consensualmente a importância da adoção de inovações pedagógicas construtivistas para o ensino médio da Física, trabalhadas em algumas disciplinas que procuram integrar os conhecimentos sobre o conteúdo aos saberes provenientes da pesquisa em educação ou da educação em ciências. Temas integradores como concepções alternativas, aprendizagem por investigação aberta envolvendo interdisciplinaridade, resolução de situações-problema, uso da História e da Filosofia da Ciência, discussão sobre visão de ciência e linguagem em sala de aula, já fazem parte, hoje, do cotidiano de muitos cursos de formação inicial e continuada espalhados por todo o país.

Durante os cursos, as disciplinas que valorizam o ensino construtivista não são suficientes para enfraquecer o senso comum pedagógico cristalizado e incentivar a adoção de práticas docentes inovadoras, havendo urgência de discussões que integrem todos os professores dos cursos em busca de caminhos para a formação de profissionais criativos e críticos para atuar com ideais construtivistas em nossas escolas. Repensar as idéias relativas à natureza da ciência em sentido amplo e em pontos mais específico é fundamental nessa busca. 
Queiroz, G. R. P. C.; Barbosa-Lima, M. C. A.

\section{Construtivismo e a etimologia da palavra}

Se for a existência da palavra escrita aquilo que possibilita o nascimento da Filosofia e da Ciência, é conveniente uma visita, por breve que seja, à formação da palavra construir, que certamente dá origem a construtivismo, assunto principal deste artigo.

Construir, semear coletivamente, se origina na palavra instruir, uma das mais antigas para indicar o processo pedagógico. Dizem Barbosa-Lima, Castro e Xavier de Araújo (2006, p. 241) que:

Do latim imperial, sec I, instruere. Surge em português no séc XVI... A palavra latina arcaica tinha, no vocabulário militar, o significado de equipar e no Latim Imperial o de informar, dar ciência, fornecer conhecimentos úteis. Ligada a instrumentum (ferramenta útil), chegou ao latim vinda de uma raiz indo-européia - str - que significa semear, lançar grãos ao solo, estender. Daí vieram palavras tão diferentes, à primeira vista, quanto: estrada, estrutura e estrela. Além, naturalmente, da palavra construir, que originalmente significava semear coletivamente. A palavra instruir, uma das mais antigas para indicar o processo pedagógico, deste belo significado original de semear, evoluiu para o sentido contemporâneo de treinamento de atividades mecânicas e repetitivas. Mas instruere não se esgota tristemente deste modo: ressurge em construir, isto é, semear coletivamente. Esta é a palavra que, nos últimos tempos, tem sintetizado e veiculado as posições pedagógicas mais avançadas.

Conhecendo o significado etimológico de construir - semear coletivamente - deduzse que o trabalho de professores das disciplinas integradoras dos conteúdos à pedagogia (como Instrumentação para o Ensino, Prática de Ensino e outras tantas que contribuem na formação profissional docente) passa por um momento de redefinições e escolhas das sementes, os grãos a serem lançados na formação docente.

\section{Construtivismo e natureza da ciência}

Gilbert et al. (2000) chamam atenção para o debate acerca da natureza da ciência introduzido pelo movimento educacional construtivista, no qual alguns pesquisadores foram qualificados como construtivistas radicais. O mais famoso entre eles, Von Glasersfeld (1996), se autoqualifica como radical ao afirmar o caráter transitório das teorias:

Defender que uma teoria do conhecimento é verdadeira, no sentido tradicional de ela representar um estado ou uma característica de um mundo independente do sujeito que nele experimenta, seria perjúrio para um construtivista radical (VON GLASERSFELD, 2006, p. 1). 
Conhecimento científico, seu ensino e aprendizagem...

Opondo-se à visão epistemológica de que o conhecimento é uma questão de sucesso no acordo entre teoria e realidade, os construtivistas radicais rejeitam veementemente tal visão, substituindo-a pela noção de viabilidade: uma teoria viável possui os atributos de coerência com outras compreensões e de ajuste com a experiência. São cuidadosos ao afirmar que toda ação, seja física ou conceitual, está sujeita a limitações impostas pelo mundo externo. Além disso, quando alguma ação falha, somos forçados a novas acomodaçoes, que implicam a formulação de novas teorias (VON GLASERSFELD, 2006).

Em meio a intenso debate, Ogborn (1995) criticou a visão radical, enfatizando que, mesmo sendo uma realização humana, e por isso não eterna ou absolutamente certa, o conhecimento científico nos permite agir com base nas afirmações confiáveis que faz sobre um mundo material.

Por reconhecer, no que ele denomina paradigma construtivista, um grande acúmulo de de dados empíricos que melhoraram o conhecimento do professor sobre os caminhos de aprendizagem de seus alunos, Osborne (1996), em seu famoso artigo Beyonds Constructivism, discutiu preocupações de ordem epistemológica relacionadas ao princípio de bivalência veiculado na Educação em Ciências por algumas propostas construtivistas radicais. Segundo tal princípio, considerado inadequado por ele, o conhecimento é verdadeiro ou falso e, como não é possível alcançar a verdade absoluta, todo o conhecimento é subjetivo, incerto e provisório. A preocupação quanto à noção de realidade a ser explicitamente adotada em qualquer proposta construtivista é parte de que uma consciência da concepção epistemológica adotada é componente importante da Educação em Ciências, uma vez que esta não deve se limitar aos conteúdos científicos, devendo também abranger os processos de sua construção.

Em seu artigo, Osborne (1996) critica o afastamento da noção de realidade, do tipo da de Von Glasersfeld (2006 e 1996), em relação à mais objetiva que possuem os principais atores do processo de construção da Ciência - os cientistas. Segundo ele, adotando ponto de vista tão contrário ao dos praticantes da Ciência, não se estaria contribuindo para a formação adequada dos futuros cientistas. Acrescenta que, tanto na Ciência como na Educação em Ciências, não basta que uma teoria seja viável para ser merecedora de consideração:

Para o cientista, teorias têm êxito porque elas oferecem um alcance explicativo não ad hoc, consistência com a evidência empírica e consistência lógica que lhes dá força explicativa... (OSBORNE, 1996, p. 59)

Demonstrando sua preocupação em deixar claro que, em Ciência, existem critérios de escolha entre teorias disponíveis, acrescenta em seguida:

O ponto aqui não é elaborar todo o critério pelo qual são julgadas as teorias, mas mostrar simplesmente que estes critérios explícitos existem e são desenvolvidos pelos cientistas quando fazem julgamentos sobre as asserções do seu conhecimento. (OSBORNE, 1996, p. 59)

Assim, Osborne (1996) contrapõe argumentos a favor de uma Educação em Ciências em que os alunos construam a idéia de que os cientistas vêm desenvolvendo maneiras racionais, claras e consistentes de avaliar suas teses, teorias, modelos etc. 
Queiroz, G. R. P. C.; Barbosa-Lima, M. C. A.

Ao debate convém trazer a proposta de Lefebvre (1975) de que a oposição formal e estéril entre conhecimento verdadeiro e falso deve ser substituída por uma concepção mais flexível, na qual os dois se encontram em interação dialética, convertendo-se um no outro, transformando-se freqüentemente, e acrescenta: "É por isso que podemos conquistar novas verdades e tender para a verdade objetiva...” (LEFEBVRE, 1975, p. 97).

Afastando-se do dogmatismo realista, do ceticismo (descrença total de que o sujeito possa apreender o objeto) ou dos relativismos (crenças da dependência do sujeito na apreensão do objeto), que pode cair até mesmo no solipsismo (consideração da existência do ponto de vista de um sujeito como o único), o relativismo dialético proposto por Lefebvre (1975) aceita um certo grau, temporário, de relatividade de nossos conhecimentos em direção à verdade. Nessa concepção, o desejo de atingi-la continua a mover o trabalho na Ciência em busca da superação dos limites do conhecimento humano, eliminando-se, desse modo, a separação entre verdade e erro e, também, a linha de demarcação entre verdade absoluta e verdade relativa. A verdade e o erro não podem ser abstratamente separados; a verdade se torna erro; o erro se torna verdade. A apreensão de uma realidade, feita de forma não ingênua, independentemente da vontade humana, torna-se fundamental para os críticos das formas radicais de construtivismo, ainda que a compreensão dessa realidade por meio da Ciência possa mudar ao longo do tempo.

Se, por um lado, a ingenuidade levaria à crença na possibilidade de se atingir completamente a realidade como ela é:

nossas produções intelectuais dependem manifestamente de informações registradas por nossos sentidos. Só que as explicações, mesmo as que se pretendem completamente escoradas pela empiria, vão além dos dados. Teorias não são elaboradas apenas com a matéria-prima dos fatos, mas também com a inventividade da razão humana. (OLIVA, 2003, p. 39)

Para o cientista Planck (apud HALBWACHS, 1976), por exemplo: "o mundo exterior não se encontra pois na base, mas no final da pesquisa em Física” (p. 28). No período inicial da Física quântica, Planck introduziu o conceito de mundo físico de Popper (1987) e Halbwachs (1976), adotado hoje por muitas correntes construtivistas: um terceiro mundo, distinto tanto do mundo real como do mundo sensível. Este mundo, diferente dos outros dois (o constituído pelos objetos e estados físicos e o constituído pelos estados mentais e pela experiências subjetivas), é uma criação consciente do homem, sujeita a transformações que pretendem levar a ciência a se aproximar cada vez mais do mundo real, num movimento de evolução histórico.

Superando a visão positivista sobre a construção do conhecimento científico, que considerava os fatos como a base segura para dar-se início à produção do conhecimento, novas soluções são difundidas para enfrentar o "problema epistemológico" acerca das relações entre mundo real e conbecimento cientifico. São consensuais (PRAIA, CACHAPUZ e GIL-PÉREZ, 2002) as idéias de que:

- Conhecimento científico é tentativo e nunca deve ser igualado à verdade; ele é apenas temporário.

- Observações isoladas não podem dar origem ao conhecimento científico de modo indutivista; vemos o mundo com lentes teóricas. 
Conhecimento científico, seu ensino e aprendizagem...

. Conhecimento novo em ciência é produzido por atos criativos de imaginação, aliados a métodos rigorosos, porém variados da pesquisa científica; sua aquisição é problemática, nunca fácil. $\mathrm{O}$ abandono do conhecimento que nos é caro e que foi falseado por algum experimento ocorre com relutância.

. O conhecimento científico novo surge no seio de uma problemática teórico-prática.

Osborne (1996) resume sua posição em relação à Educação em Ciências: deve-se tentar não só comunicar a prática da ciência, mas também as convicções amplamente sustentadas na comunidade científica; o conhecimento científico tem uma posição diferenciada em relação a outras formas de conhecimento e, para mantê-la, os cientistas adotam um programa de experimentação, verificação e revisão atenta, em busca de consensos, que são a pedra de toque de confiabilidade no conhecimento científico. De modo a propor uma visão de realidade, Osborne (1996) revisita o realismo para emergir com um realismo moderado que não pretende mais responder a questões sobre a veracidade de uma teoria. "Mas ao invés disso, fazer a pergunta: existem coisas, propriedades, processos deste tipo?” É desse modo que os cientistas conseguem defender as proposições que fornecem e é nesse caminho que os professores poderão argumentar com seus alunos a favor da atualidade do conhecimento ensinado e aprendido.

Filósofos da Ciência como Laudan (1977), apoiados em laboratórios de História e de Sociologia da Ciência, que vêm produzindo trabalhos de valor em escala crescente, têm estabelecido alguns critérios que evitam tanto o irracionalismo como relativismos extremos para decidir entre teorias concorrentes a explicar satisfatoriamente um conjunto de dados a elas relacionados.

Laudan (1977), partindo do pressuposto de que a ciência evolui a partir do surgimento e da busca de soluções de novos problemas que surgem em diferentes contextos, retoma a discussão do papel de uma anomalia nos momentos de evolução científica, embora nem sempre o seu surgimento acarrete necessariamente o abandono da teoria vigente, relativizando a primazia entre teoria e empiria.

Para Laudan (1977), usualmente diz-se que, se uma Teoria $T_{1}$, ao encontrar uma instância empírica refutadora, é modificada, gerando uma Teoria $\mathrm{T}_{2}$ que apenas resolve a anomalia, sem solucionar problemas novos, não houve progresso. A nova teoria, que transforma a anomalia em solução para o problema não resolvido por sua antecessora, é considerada $a d$ hoc ${ }^{4}$ se seu papel se limitar a resolver o problema que, de certa forma, a gerou. Tais teorias chegam a ser denominadas de "ociosas", mas para Laudan (1977), mesmo assim trouxeram algum progresso ao aumentarem a capacidade da Ciência quanto ao número de problemas cognitivos resolvidos. Reconhece, no entanto, que o progresso é questionável porque os ganhos de uma nova teoria vêm, em geral, acompanhados de perdas pelo desinteresse que velhos problemas passam a ter em contextos novos.

${ }^{4} A d$ boc $=$ para este caso. Diz-se que uma teoria é ad hoc quando não cria novos problemas que ela mesma possa resolver, limitando-se a resolver a anomalia para a qual foi criada e os problemas empíricos que a teoria anterior já resolvia. 
Queiroz, G. R. P. C.; Barbosa-Lima, M. C. A.

Diferentemente de teorias ad hoc, surgem novas Teorias $\mathrm{T}_{\mathrm{n}}$ que, ao modificarem conceitos, se tornam mais abrangentes, inclusive empiricamente, suplantando tanto $\mathrm{T}_{1}$ como $_{2}$ na capacidade de resolver problemas, devendo-se computar, nessa vitória, problemas empíricos e conceituais. Assim, Laudan estabelece um critério mais amplo para que uma teoria seja considerada mais viável do que outras concorrentes, indo ao encontro da idéia de Lefebvre (1975) de que o empirismo tem razão ao enfatizar a relevância do mundo sensível, embora não tenha razão ao negar que seja necessário superá-lo. Os fatos do mundo sensível podem continuar sendo os mesmos e não gerar mais problemas para a Ciência.

Novos problemas conceituais são caracterizados por filósofos da Ciência como dificuldades apresentadas por uma teoria, podendo ser internas - inconsistências ou categorias vagas - ou externas - conflito com outra teoria considerada mais sólida. Assim, um objetivo a ser perseguido para o crescimento do valor dado a uma teoria passa por minimizar problemas conceituais. Problemas empíricos, no entanto, continuam a fazer parte do jogo da Ciência: a eficácia de teorias concorrentes, segundo Laudan (1977), é calculada pela diferença entre o número e importância dos problemas empíricos que a teoria resolve menos o número e a importância das anomalias e problemas conceituais que a teoria gera. Quando o primeiro termo aumenta e/ou o segundo diminui, podemos dizer que uma nova teoria trouxe progresso em relação a suas rivais. ${ }^{5}$

\section{Construtivismo e aprendizagem das Ciências}

Ao se reconhecer o fato de que o suporte teórico conhecido como Construtivismo está por trás da maioria dos trabalhos no âmbito da Didática das Ciências, vale a pena organizar a sua polissemia. É possível avançar em relação ao trivial na etiqueta construtivista por se temer que ela "pode terminar por converter-se em um termo vago e impreciso se a afirmação de que o sujeito constrói o conhecimento não for recheada de conteúdo mais preciso" (MARÍN MARTÍNEZ, 2003, p. 49). Em princípio é importante se distinguir o construtivismo que busca compreender como o conhecimento é construído na mente do sujeito e aquele originado numa comunidade científica que regula de modo característico sua produção, sendo toda a produção afetada por uma série de fatores econômicos, históricos etc. Os principais matizes dos tipos de construtivismo que se tornaram importantes para a didática das ciências foram: o piagetiano, o bumanista, ${ }^{6}$ o social (inicialmente Movimento das concepsões alternativas, $M C A$ ) e o radical.

\footnotetext{
${ }^{5}$ Vale lembrar que Laudan (1977) tem, nas tradições de pesquisa, a ferramenta básica para compreender e apreciar o progresso científico. Cada tradição considerada contém uma quantidade de teorias específicas que a exemplifica, e compromissos metafísicos e metodológicos que a individualizam.

${ }^{6}$ A aprendizagem significativa em uma visão humanista ganha destaque na teoria de Novak (1981) e procura levar em conta que o ser humano conhece, sente e age, não sendo apenas cognitivo.
} 
Conhecimento científico, seu ensino e aprendizagem...

Marín Martínez (2003) vai buscar as bases epistemológicas, psicológicas e pedagógicas dos quatro tipos por ele considerados, para reorganizá-los em duas novas categorias: construtivismo estático e construtivismo dinâmico. O primeiro assume que aquilo que o sujeito apreende ou interpreta da realidade depende de seus conhecimentos anteriores, dividindo o todo em partes, por meio de mecanismos reducionistas/mecanicistas. Nele supõem-se que o todo é simplesmente a soma das partes, sem levar em consideração a configuração estabelecida entre as partes.

Para as propostas consideradas pelo autor dentro do construtivismo estático, as interações do sujeito com novos materiais (texto, explicações, experiências), com o intuito de que a aprendizagem seja significativa, levam em conta o conhecimento prévio dos estudantes, acreditando-se, porém, que o novo conhecimento será construído por conexões ou associações entre o que os alunos trazem e o conhecimento científico dos currículos, considerado imutável durante o processo de aproximações progressivas, daí a sua qualificação como construtivismo estático.

O construtivismo dinâmico assume inicialmente, como o estático, que o conhecimento novo do sujeito se constrói em interação com o conhecimento anterior, porém rechaça o princípio de correspondência entre realidade prévia e conhecimento novo, abordando o problema numa perspectiva orgânica que integra valores e novas visões de mundo. Rejeita ainda a analogia da mente como um processador de informações, mas busca conhecer a construção e modificação constante da estrutura cognitiva dos sujeitos, usando, para isso, os processos de assimilação e acomodação piagetianos como referência básica. Segundo Marín Martínez (2003, p. 45), "a teoria da equilibração de Piaget poderia se enquadrar dentro do construtivismo dinâmico".

Pozo (1996) adota posição ainda mais ampla ao defender que, na aprendizagem cotidiana e na educação, a aprendizagem associativa e a aprendizagem construtiva estão presentes. Porém acrescenta: "a aprendizagem construtivista produz resultados mais sólidos e significativos que outras formas de aprendizagem, em definitivo é uma aprendizagem mais eficaz..." (p. 133).

Planejar uma nova didática para a educação em Ciências tem sido objeto de estudo de pesquisadores ao longo das últimas décadas. Nos últimos anos, ao fazerem da sala de aula seu campo de pesquisa, passaram a enfocar o professor, seus argumentos, sua linguagem, seus procedimentos didáticos mais gerais, enriquecendo a pesquisa e deixando clara a diferença de objetivos do professor e do pesquisador (QUEIROZ, GUIMARÃES e FONTE BOA, 2001), mostrando, mais uma vez, a conveniência de se tratar como sistemas complexos as situações de ensino-aprendizagem.

A compreensão dos processos desenvolvidos pelos cientistas, como a identificação e o controle de variáveis, o tratamento dos dados empíricos - médias, cálculo de erros de medida etc -, a geração de hipóteses viáveis, entre outros, pode assim continuar a ser valorizada por professores cujo objetivo se mantém aliado a uma racionalidade construtivista.

\section{Construtivismo e pesquisa em educação em ciências}

Nos anos de 1980, surgiu o movimento das concepções alternativas (MCA), dando espaço às experiências prévias dos indivíduos e às capacidades específicas, em vez de colocar 
Queiroz, G. R. P. C.; Barbosa-Lima, M. C. A.

a aprendizagem em ciência como dependente apenas de funcionamento cognitivo generalizado. Ele se iniciou a partir de uma crítica tanto ao empirismo na educação em ciências, que adota uma visão rígida e não atualizada da produção da ciência, quanto ao construtivismo piagetiano, criticado sobretudo na Inglaterra por ser de domínio geral, não atendendo a especificidades dos conteúdos. O MCA desenvolveu-se com rapidez quase exponencial (OSBOR$\mathrm{NE}, 1996)$, oferecendo um novo enfoque à educação em ciências centralizado no poder de recuperação das idéias dos alunos.?

Trabalhou-se tanto sob este referencial teórico, que temos, hoje em dia, graças ao MCA, um excelente mapeamento ou, em outras palavras, um diagnóstico bastante preciso sobre a conceituação de senso comum trazida pelos alunos para a escola (CARMICHAEL et al., 1990). No entanto, em vez de se acreditar na substituição, na mentalidade dos alunos, de uma concepção alternativa por uma cientificamente aceita, no processo conhecido como mudança conceitual, pesquisas na área levaram inicialmente a acreditar que os dois "pensamentos" podiam conviver e seriam mobilizados em situações em que eram considerados mais adequados.

As pesquisas de Pozo (POZO, 1998; POZO E GÓMEZ CRESPO, 1996) o levaram a avançar em relação ao modelo anterior, de independência contextual, propondo um enfoque para o ensino de ciências por explicação e contrastação de modelos e integração hierárquica entre o conhecimento científico e o que os alunos trazem para a escola. Para isso, usou os pressupostos epistemológicos de um construtivismo que concebe o processo de construção da ciência como o de elaboração de modelos - a modelagem - aos quais certos fenômenos naturais ou simulados são submetidos, num diálogo contínuo em busca de ajuste teórico ao que nós conhecemos da realidade. Porém, assim como Marín Martínez (2003), não aceita um isomorfismo entre a construção do conhecimento científico e o dos alunos, por reconhecer que cada um é construído em cenários diferenciados, por comunidades que atendem a critérios diferentes.

Atualmente, a meta da educação científica consensual, entre muitos pesquisadores, é que os alunos conheçam a existência de diversos modelos alternativos na interpretação e compreensão da natureza, sendo apresentados aos modelos da ciência, contrastando-os com os seus e com outros historicamente existentes. Isso os ajudará não só na compreensão mais clara do que é estudado, como ainda colaborará para um melhor entendimento das formas de construção da ciência. A referida integração bierárquica só poderá se dar se os alunos forem levados a entender seus modelos e concepções prévias à luz dos modelos consensuais da ciência.

\section{Ensino de Ciências na sala de aula}

Nos dias de hoje, é incontestável que não só as críticas da nova filosofia da ciência influenciaram a educação em ciências, como as estratégias de ensino-aprendizagem adotadas no âmbito da sala de aula, sob enfoques construtivistas, vêm oferecendo novas idéias sobre a

\footnotetext{
${ }^{7}$ No Brasil, onde desde os anos 1970 estudos piagetianos já eram objeto de trabalho de vários pesquisadores em educação em ciências, ao se tomar conhecimento das principais diretrizes do MCA, muitas articulações foram estabelecidas, procurando-se integrar as duas abordagens teóricas.
} 
produção do conhecimento científico pelos alunos. Desse modo, a relação entre a epistemologia da prática docente em ciências e seu ensino-aprendizagem torna-se uma via de mão dupla. Conhecem-se, hoje, diferentes propostas para a busca mais eficiente de aprendizagens significativas de conhecimento científico pelos alunos, corroborando idéias filosóficas que, mesmo sem defender a descrição última da realidade, não tiram da ciência seu valor de verdade construída por uma comunidade e passível de sofrer reformulações diante de novas evidências factuais ou desenvolvimentos teóricos. Para tal, construtivistamente, admite-se que "todos os produtos da pesquisa científica são frutos de tentativas de estruturar representações sobre o mundo e sofrem modificações de tempos em tempos" (PIETROCOLA, 2002, p. 106).

Na perspectiva da complexidade da sala de aula, pesquisadores vêm realizando atividades que apresentam o conhecimento científico como recurso capaz de levar os alunos a tomarem consciência das variáveis envolvidas, da forma de controlar as que são passíveis de controle e, assim, conseguirem resolver problemas. Uma situação-problema é concebida como uma tarefa que envolve, de forma obrigatória, pelo menos uma aprendizagem significativa (CAPECCHI e CARVALHO, 2000; BARBOSA-LIMA, 2001; CARVALHO et al., 1998; GILPÉREZ e VALDÉS CASTRO, 1997). Tal situação é vista, pelos professores, como um meio de fazer seus alunos chegarem a aliar a Ciência estudada com a vida que lhes cerca, fazendo uso de métodos cuidadosos e da imaginação, que podem conduzir à solução dos problemas originados das mais variáveis formas.

E do ponto de vista do aluno? O que é um problema? Para o aluno, normalmente habituado à solução de exercícios, e não de problemas, essa nova estratégia, em geral, os mobiliza a estabelecerem diálogos no mundo das hipóteses, vivenciando processos autenticamente construtivistas. Contribuições de autores de divulgação de ciências ou da literatura mais ampla têm trazido problemas que, de fato, podem instigar os estudantes com a apresentação de um problema plausível. Por exemplo, como no caso da coletânea de contos Aventuras Cientificas de Sherlock. Holmes (BRUCE, 2000), onde, logo na primeira história, o próprio Holmes precisa da ajuda de um cientista para tomar conhecimento do funcionamento do pêndulo de Foucault para conseguir resolver o enigma em que seu cliente está envolvido - uma morte causada por um ferimento produzido por um pêndulo encontrado em uma trajetória aparentemente improvável de haver causado o acidente fatal.

No que se refere explicitamente ao "método científico", professores e pesquisadores das salas de aula não devem mesmo abandoná-lo de todo, porém não se admite que ignorem as críticas da sua unicidade, a ele feitas durante mais de meio século de discussões. A crença de que um só caminho seja capaz de conduzir a descobertas verdadeiras e passíveis de serem justificadas ao público especializado e geral deve ser substituída por um processo que reconheça a impossibilidade de se eliminar completamente o papel do sujeito na construção do conhecimento, sem chegar a relativismos radicais do tipo dos que sustentam uma incomensurabilidade, entre teorias concorrentes, que impossibilita uma avaliação comparativa entre elas.

Nesse caminho, abandonando a crença num método único e infalível, e adotando um relativismo moderado, que admite critérios epistemológicos e racionais para julgar a validade da versão vigente de conhecimento científico, pesquisadores em Ciência e em Educação em Ciências reconhecem a adoção, na produção de Ciência, de algumas regras, e mais do que isso, assumem o compromisso dos cientistas com a comunidade à qual pertencem com um rigor indispensável à produção e validação de conhecimento. Processos de construção de conhecimento diversificados são evidenciados por pesquisadores tanto nos estudos de Epistemologia 
Queiroz, G. R. P. C.; Barbosa-Lima, M. C. A.

Genética piagetiana como nos de História da Ciência. Algumas convergências entre eles e entre as idéias de crianças e de cientistas do passado devem fazer parte da educação em ciências destinada a preparar indivíduos e comunidades aptas a enfrentarem as discussões que a demarcação entre Ciência e não Ciência suscita, uma vez que, diante dos mesmos fatos, vamos encontrar, na História, assim como nas crianças, teorias diferenciadas. Segundo Giordan et al. (1983, p. 23), "a abordagem histórica é um bom quadro de referência para estudar, por comparação, os processos de aprendizagem na criança”.

Entre outras formas construtivistas de mediar a produção do conhecimento do aluno, está a modelagem analógica de fenômenos, que permite aos estudantes identificarem características e propriedades de seus modelos, comparando-os com os propostos pelos professores (QUEIROZ, 2000). Os modelos são o núcleo que organiza esse enfoque e há um interesse explícito nos conteúdos conceituais que favorecem a sua construção. "Conhecer uma situação é representá-la por um modelo" (HALBWACHS, 1976, p. 31). Dessa maneira, essa abordagem pode se articular com a solução de situações-problema, enfatizando-se que o conceito de representação aqui envolvido implica certa correspondência entre aspectos do "real" e do conhecimento científico.

Podemos considerar que as explicações científicas possuem a mesma estrutura lógica de um argumento cujo conjunto de enunciados se concatenam entre si, de modo que o conclusivo seja conseqüência dos que o antecederam (OLIVA, 2003). Argumentos indutivos ou dedutivos são modos de comunicação verbais usados na sala de aula e reconhece-se esse ambiente como espaço social de negociação de novos significados.

Análises de cunho sociohistórico dos processos de produção do conhecimento são mobilizadas durante as aulas para motivar os alunos a julgarem seus conceitos, sua visão de ciência e de função da educação em ciências. Professores lançam mão de toda essa gama de recursos para rechear as discussões em aula, cientes de que assim como fazer ciência, também aprender ciência é "falar ciência" (DRIVER et al., 1999; LEMKE, 1997), argumentando e convencendo ou sendo convencido. Mortimer e Scott (2002) têm pesquisado as diferentes formas, verbais e não verbais, pelas quais se dão as interações entre docentes e estudantes ao tratarem os conteúdos científicos.

Pesquisadores construtivistas dedicados a conhecerem o que leva os estudantes a atribuírem significado aos conteúdos (uso de analogias, metáforas, experimentos etc.), ao entrarem nas salas de aula (MORTIMER, 2002; QUEIROZ, 2000), puderam perceber a importância do que passou a ser chamado de uma nova retórica, o conjunto articulado de diferentes modos de comunicação, tais como linguagem argumentativa, imagens, gestos, usados para produzir "textos" coerentes que comunicam, ensinam e legitimam o conhecimento científico escolarizado.

\section{Construtivismo e formação de professores}

Esperamos que o Construtivismo, na sua versão dinâmica, chegue aos bancos escolares, e o que nos compete fazer para que isso aconteça passa pela formação dos professores de ensino médio que oferecemos ao mercado de trabalho a cada ano.

Nossos alunos universitários que optam pela formação em Licenciatura em Física chegam aos últimos semestres do curso com seus conceitos prévios do que é ser professor. 
Conhecimento científico, seu ensino e aprendizagem...

Normalmente, a caracterização do profissional do magistério trazida é traduzida pelo estereótipo do professor tradicional que lhes serviu de exemplo pelo já longo tempo de escolarização. Assim sendo, a maioria deles acredita que a aula deve ser dada, quase no sentido estrito de doação do saber do professor para os alunos, que a receberão passivamente e que são considerados detentores de nenhum saber.

No curso inicial de formação de professores, é comum que, ao ouvirem falar em Construtivismo, os alunos expressem críticas que consideram essa perspectiva como deixando a cargo dos alunos uma responsabilidade quase exclusiva pela construção de um conhecimento científico particularizado e, portanto, fortemente marcado pelo sujeito da aprendizagem. Com as sementes construtivistas lançadas nos cursos de formação universitária, em especial nas disciplinas integradoras, como a Instrumentação para o ensino e a Prática de Ensino, os futuros docentes começam a se perceber construtores de um conhecimento pedagógico de conteúdo (LOUGHRAN, BERRY e MULHALL, 2005) com significado, um conhecimento que, em muito, se diferencia do que lhes foi proporcionado pela maioria das disciplinas do currículo. Com isso, fica aberto o caminho para que inovações pedagógicas construtivistas sejam realizadas.

\section{Construtivismo e complexidade}

Piaget também discordou do credo comum a todas as formas de empirismo: a observação sensorial é a fonte primeira e o último juiz de todo o conhecimento. Nem apriorismo, nem empirismo; assim se posiciona Piaget em relação à produção do conhecimento (GARCIA, 2002). Segundo o princípio piagetiano de continuidade funcional dos processos construtivos, não havendo um ponto de partida do qual o conhecimento se origina, a aquisição do conhecimento em todas as etapas de desenvolvimento, não apenas da infância até a idade adulta - para os chamados cidadãos comuns - mas até o nível dos cientistas, é estudada por meio de seus mecanismos construtivos comuns. A validação com exemplos históricos dessa afirmação foi realizada por Piaget e Garcia (1983) no livro Psychogènese et histoire des sciences.

A proposta construtivista apoiada na análise psicogenética (GARCIA, 2002) implica que o conhecimento seja estudado como um processo cujo desenvolvimento está fortemente atrelado ao contexto histórico-social (marco epistêmico), não se limitando, assim, a epistemologia construtivista, aos métodos de validação aos quais o empirismo se reduziu.

Entre os "mecanismos comuns" aos dois tipos de construção (individual e histórica), que Piaget e colaboradores buscam relacionar com o princípio da continuidade funcional, estão dois processos básicos: assimilação (dos objetos aos esquemas de ação) e acomodação (dos esquemas às propriedades dos objetos), envolvendo, dessa maneira, a produção pelo sujeito de novos esquemas de ação em função dos objetos, numa relação bidirecional indissociável entre sujeito e objeto. Outros mecanismos comuns são designados com os nomes clássicos de abstração e generalização (GARCIA, 2002; PIAGET e GARCIA, 1983).

\footnotetext{
${ }^{8}$ Nesse sentido, a crítica enfatiza o fato de o construtivismo piagetiano não ser aplicável à escola e às salas de aula, pois nelas os professores percebem que as dificuldades dos estudantes não são as mesmas de um campo conceitual para o outro (MOREIRA, 2002).
} 
Ao reduzir a complexidade conceitual em vários campos do conhecimento científico a um tipo de complexidade lógica geral, o construtivismo piagetiano tem sido considerado determinista e incapaz de dar conta das diferenças que ocorrem em função do conteúdo do conhecimento cujo processo de construção na ciência (ou no indivíduo) se deseja conhecer. ${ }^{6}$ Para Rolando García, ao final da vida de Piaget, a epistemologia genética passou de uma teoria descritiva da sucessão de formas organizativas (estrutura) lógicas, os estádios, a uma teoria de processos envolvidos na dinâmica da sucessão, dada pelos mecanismos. Em seu livro de 2002, Garcia amplia e sistematiza a Epistemologia Genética como teoria científica integrada, propondo-se a atualizar e desenvolver áreas que se mostraram incompletas, oferecendo uma teoria complexa de base piagetiana mais frutífera para ser mobilizada na prática. Disponibiliza indicações metodológicas preciosas para realizar e avaliar pesquisas sobre sistemas complexos em uma visão construtivista multidisciplinar, trazendo, ao conhecimento dos seus leitores, a semi-autonomia dos níveis de organização, conhecida como "desacoplamento", além de princípios para caracterizar os níveis de diferentes subsistemas de um mesmo sistema complexo e as interações entre eles.

Moreira (2002) tem trazido a perspectiva teórica dos campos conceituais de Vergnaud como possível referencial para o ensino de ciências e para a pesquisa nessa área. Considerando o conceito piagetiano de esquema como a pedra angular para a investigação, Vergnaud toma a conceitualização como o âmago do desenvolvimento cognitivo. Segundo Moreira (2002),

trata-se de uma teoria psicológica do processo de conceitualização do real, que permite localizar e estudar continuidades e rupturas entre conhecimentos do ponto de vista do seu conteúdo conceitual.... qualquer reducionismo é perigoso na medida em que a conceitualização do real.... não pode ser reduzida nem às operações lógicas gerais, nem às operações puramente lingüísticas, nem à reprodução social, nem à emergência de estruturas inatas, nem, enfim, ao modelo do processamento da informação. Conseqüentemente, a teoria dos campos conceituais é uma teoria complexa. (MOREIRA, 2002, p. 2)

Um dos argumentos que levou Vergnaud ao conceito de campo conceitual foi a constatação de que a construção e a apropriação de todas as propriedades de um conceito ou todos os aspectos de uma situação são um processo longo e que requer muito fôlego, muitas idas e vindas na distinção do que foi tecido junto (o complexus). Para Vergnaud, o desenvolvimento cognitivo, no fundo, é o desenvolvimento de um vasto repertório de esquemas (com seus ingredientes: metas e antecipacõos; regras de ação do tipo se [...] então; invariantes operatórios que dirigem o reconbecimento e possibilidades de inferencia ou raciocinios ) com os quais os sujeitos interagem com diferentes situações complexas.

Como vemos, Vergnaud (apud MOREIRA, 2002) e Garcia (2002) propõem abordagens da construção do conhecimento dentro de um paradigma considerado emergente, o da complexidade. Nele, o estudo dos sistemas cognitivos constituem recortes da realidade feitos pelo pesquisador segundo metodologias apropriadas.

A educação científica tem se caracterizado por abordagens fragmentárias, nas quais os conteúdos de diferentes áreas do conhecimento são apresentadas de forma desconectada (MORAES, 2003). Em uma mesma disciplina, programas e ementas subdividem os temas em 
tópicos independentes. As relações temporais, espaciais, políticas e históricas, entre assuntos no âmbito de uma disciplina e nos de umas com as outras, são geralmente ignoradas, impedindo a compreensão do mundo em que vivemos. Enfoques multidisciplinares ou interdisciplinares, que já se constituem em avanços em relação à fragmentação, em alguns casos insistem em integrar o conhecimento apenas propondo a escolha de temas para os quais devem convergir as diferentes disciplinas, sem aprofundar as relações entre elas. Pesquisadores como Moraes (2003) avançam com a perspectiva da abordagem relacional, na qual a integração dos conhecimentos disciplinares passa a ser o próprio objeto do conhecimento a ser construído. Consideram que, desse modo, a percepção e a compreensão da complexa rede de conexões dos componentes físico-químicos, biológicos e humanos do nosso planeta se tornam possíveis.

\section{Considerações finais}

Em suma, uma posição epistemológica aceitável para nossos propósitos pedagógicos pode ser resumida como aquela que considera que o conhecimento se constrói por interações entre sujeitos e objetos pertencentes a uma realidade na qual estamos inseridos como sujeitos, sendo ela repleta de inumeráveis e imprevisíveis mudanças e transições (LEFEBVRE, 1975). Como resultado dessas interações, construímos modelos de como vemos o mundo externo a nós. Qualquer informação nova que absorvemos do ambiente está sempre marcada pelas vivências que tivemos ou que estamos tendo no momento. Tal concepção, construtivista, nos leva a um afastamento tanto do empirismo - concepção segundo a qual a origem do conhecimento está na experiência sensorial - como do racionalismo, que reúne diferentes concepções que possuem, em comum, a crença de que a construção do conhecimento se inicia na mente/ razão do sujeito. No Construtivismo que adotamos, o conceito da Ciência como mundo físico passa a ter existência independente de nós que a criamos, mantendo-se compromissos empíricos com a cultura reconhecida oficialmente pelas comunidades científicas. Cada elemento dessa cultura foi elaborado com finalidade determinada e está sujeito a transformações que pretendem levar a Ciência a se aproximar, cada vez mais, de um mundo real, num movimento de evolução histórico que, hoje em dia, admite novas realidades - partículas e eventos - trazidas pelo avanço da Física, da Biologia ou da Química. Essa idéia tem o apoio de muitas correntes na filosofia das ciências e entre cientistas, como no caso de Einstein e Infeld (1976):

A ciência não é apenas uma coleção de leis, um catálogo de fatos não relacionados entre si. É uma criação da mente humana, com seus conceitos e idéias livremente inventados. (EINSTEIN e INFELD, 1976 p. 235)

Assim como na descrição da aquisição do conhecimento, o Construtivismo - cujas bases defendemos neste trabalho - e a formação de professores realizada sob seus parâmetros sofrerão mudanças ao longo do tempo, num processo que esperamos seja de contínua articulação desse movimento em novas formas bem-sucedidas de ensinar e aprender e que, apesar de suas nuances, mantém importantes instâncias que o corroboram na prática pedagógica de salas de aula inovadoras. 
Queiroz, G. R. P. C.; Barbosa-Lima, M. C. A.

Para que um paradigma se estabeleça e frutifique, é urgente o engajamento dos seus praticantes em novas articulações cada vez mais enredadas nas áreas socioculturais, nas quais saberes criados na formação inicial ou na experiência pedagógica sejam mobilizados e recriados, gerando inovações indispensáveis para a evolução de uma educação em ciências desenvolvida para a complexidade crescente que o mundo contemporâneo projeta sobre todos nós.

As implicações para uma didática das ciências construtivista e para a formação de professores aptos a mobilizá-la com seus futuros alunos passam pelo reconhecimento da necessidade do ensino-aprendizagem de conhecimentos e processos científicos universais, que são importantes não só para a solução de problemas do cotidiano como também permitem aos indivíduos se tornarem cidadãos críticos em relação à sociedade mais ampla. Ao possuírem mais informações provenientes do campo científico, os alunos podem refinar seus modelos e contar, de novas maneiras, uma história mais rica sobre como se organiza o mundo em que vivemos.

Ao fazermos a escolha epistemológica para dar suporte a estratégias adotadas numa educação em ciências construtivista, mostramos uma via de mão dupla entre a pedagogia e uma concepção quanto à concepção de realidade, aceitável tanto pela comunidade científica quanto pela maioria dos professores de ciências. Com a concepção adotada, apresentamos processos de escolha entre teorias concorrentes que podem ser trabalhadas com os alunos, de modo a aumentar a confiança a elas destinadas em função da validade dos resultados e dos processos desenvolvidos no âmbito da Ciência. Assim, esperamos contribuir para que o construtivismo continue engendrando novas estratégias de ensino-aprendizagem.

Finalizamos incitando a realização de novas pesquisas que intensifiquem as relações entre pesquisadores em educação em ciências de diferentes linhas de pesquisa com os da educação em geral, sugerindo que, para isto, se aprofundem estudos sobre os sistemas complexos e os princípios que procuram estabelecer formas características para o seu funcionamento, diferenciando níveis de organização de subsistemas semi-autônomos, com dinâmicas próprias, porém interatuantes. A compreensão do "desacoplamento" entre as teorias desenvolvidas para os subsistemas de sistemas complexos pode evitar as constantes tentativas de "demolições" de referenciais teóricos que pesquisadores de diferentes áreas costumam desencadear.

Tanto no mundo da ciência como no da educação em ciências e na formação de professores de ciências, o relativismo dialético de Lefebvre (1975), estando presente, nos faz relembrar também da relatividade de nossos conhecimentos, levando-nos de volta à raiz str (semear) do vocábulo construtivismo, pois cada etapa do desenvolvimento da Ciência traz, com ela, novos grãos semeados por pesquisadores e professores em seus laboratórios ou salas de aula. Semeando, cada vez mais, grãos com os instrumentos construtivistas que geramos, podemos esperar uma colheita de verdades temporárias confiáveis pelo seu valor atual, apesar de entendermos que poderão sofrer mutações para próximas semeaduras e colheitas. 
Conhecimento científico, seu ensino e aprendizagem...

\section{Referências}

AUSUBEL, D. P. Educational Psychology: a cognitive view. New York: Holt, Rinehart e Winston, 1968.

BARBOSA-LIMA, M. C. Explique o que tem nessa história. 2001. 150f. Tese (Doutorado em Educação) - Faculdade de Educação, Universidade de São Paulo, São Paulo, 2001.

; CASTRO, G. F.; XAVIER DE ARAÚJO, R. M. Educar, formar, educar e instruir: a linguagem da crise escolar. Ciência \& Educação, Bauru, v. 12 , n. 2, p. 235-245, 2006.

BRUCE, C. As aventuras de Sherlock Holmes. Rio de Janeiro: Jorge Zahar, 2000.

CAPECCHI, M. C. V. M.; CARVALHO, A. M. P. Argumentação em uma aula de conhecimento físico com crianças na faixa de 8 a 10 anos. Investigações em Ensino de Ciências, Porto Alegre, v. 5, n. 3, p. 171-189, 2000.

CARMICHAEL, P. et al. Research on student's conceptions in science: a bibliography Leeds: University of Leeds, 1990.

CARVALHO, A. M. P. et al. Ciências no Ensino Fundamental. São Paulo: Scipione, 1998.

DRIVER, R.; ASOKO, H.; LEACH, J.; CASTILHO, D. H. Construindo conhecimento científico na sala de aula. Química Nova na Escola, São Paulo, n. 9, p. 31-40, 1999.

EINSTEIN, A.; INFELD, L. A evolução da Física. 3. ed. Rio de Janeiro: Jorge Zahar, 1976.

GIL-PÉREZ, D.; VALDÉS CASTRO, P. La resolución de problemas de física: de los ejercicios de aplicación al tratamiento de situaciones problemáticas. Revista Enseñanza de la Física, Buenos Aires, v. 10, n. 2, p. 5-20, 1997.

GARCIA, R. O conhecimento em construção: das formulações de Jean Piaget à teoria de sistemas complexos. Porto Alegre: Artmed, 2002.

GILBERT, J. et al. Science and education: notions of reality, theory and model. In: GILBERT, J.; BOULTER, C. (Eds.). Developing models in science education. London: Kluwer Academic Publishers, 2000. p. 3-17.

GIORDAN, A. et al. L'Élève et/ou les connaissances scientifiques: approche didactique de la construction des concepts scientifiques par les élèves. Bern: Peter Lang, 1983.

HALBWACHS, F. El pensamiento físico en el niño y en el sabio Valencia: Editorial Marfil, 1976.

LAUDAN, L. Progress and its problems. Berkley: University of California, 1977. 
Queiroz, G. R. P. C.; Barbosa-Lima, M. C. A.

LEFEBVRE, H. Lógica formal, lógica dialética. Rio de Janeiro: Civilização Brasileira, 1975.

LEMKE, J. Aprender a hablar ciencia: lenguaje, aprendizaje y valores. Barcelona:

Ediciones Paidós Ibérica, 1997.

LOUGHRAN, J.; BERRY, A.; MULHALL, P. Knowledge to enhance science teaching and learning: pursuing scholarship through explicity enacting expert science teachers' pedagogical content knowkedge. In: EUROPEAN SCIENCE EDUCATION RESEARCH ASSOCIATION, 2005, Barcelona. Proceedings ... Barcelona, 2005. v. único.

MARÍN MARTÍNEZ, N. Visión constructivista dinámica para la enseñanza de las ciencias. Enseñanza de las ciencias, Barcelona, v. 21, n. extra, p. 43-55, 2003.

MARTÍ, E. El constructivismo y sus sombras. Anuario de Psicología, Barcelona, n. 26, p. 3-18, 1996.

MORAES, R. Construtivismo e ensino de Ciências. Porto Alegre: EDPUCRS, 2003.

MOREIRA, M. A. A teoria dos campos conceituais de Vergnaud, o ensino de ciências e a pesquisa nesta área. Investigações em ensino de ciências, v. 7, n. 1, 2002. Disponível em: <http://www.if.ufrgs.br/ienci>. Acesso em: 05 de junho de 2002.

MORTIMER, E. F. Uma agenda para a pesquisa em educação em ciências. Revista Brasileira de Pesquisa em Educação em Ciências, Porto Alegre, v. 2, n. 1, p. 36-59, 2002.

Linguagem e formação de conceitos no ensino de Ciências. Belo Horizonte: Editora UFMG, 2000.

.; SCOT'T, P. Atividade discursiva nas salas de aula de ciências: uma ferramenta sociocultural para analisar e planejar o ensino. Investigações em Ensino de Ciências, v. 7, n. 3, 2002. Disponível em: <http:/www. if.ufrgs.br/public/ensino>. Acesso em: 05 de novembro de 2002

NOVAK, J. D. Uma teoria de educação. São Paulo: Pioneira, 1981.

OGBORN, J. Recovering reality. Studies in Science Education, Ithaca, Cornell University Press, v. 25, p. 3-38, 1995.

OLIVA, A. Filosofia da Ciência. Rio de Janeiro: Jorge Zahar, 2003.

OSBORNE, J. F. Beyond constructivism. Science Education, Sidney, v. 80, n. 1, p. 53-82, 1996.

PIAGET, J.; GARCIA, R. Psychogènese et Histoire des Sciences. Paris: Flamarion, 1983. 
Conhecimento científico, seu ensino e aprendizagem...

PIETROCOLA, M. A Matemática como estruturante do conhecimento físico. Caderno Brasileiro de Ensino de Física, Florianópolis v. 19, n. 1, p. 93-114, 2002.

POPPER, K. R. O realismo e o objectivo da Ciência: pós-escrito à lógica da descoberta. Lisboa: Publicações Dom Quixote, 1987.

POZO, J. I. No es oro todo lo que reluce ni se construye (igual todo lo que se aprende): contra el reduccionismo constructivista. Anuario de Psicología, Barcelona, n. 26, p. 127-139, 1996.

.; GÓMEZ CRESPO, M. A. Aprender y enseñar ciencias. Madrid: Morata, 1998.

PRAIA, J. F.; CACHAPUZ, A. F. C.; GIL-PÉREZ, D. Problema, teoria e observação em Ciência: para uma reorientação epistemológica da educação em ciência. Ciência $\boldsymbol{\&}$ Educação, Bauru, v. 8, n. 1, p. 127-145, 2002.

QUEIROZ, G. Professores artista-reflexivos de Física no Ensino Médio. 2000. 330 f. Tese (Doutorado) - Pontifícia Univesidade Católica, Rio de Janeiro, 2000.

.; GUIMARÃES, L. A.; FONTE BOA, M. O professor artista-reflexivo de Física: a pesquisa em ensino de Física e a modelagem analógica. Revista Brasileira de Pesquisa em Educação em Ciências, Porto Alegre v. 1, n. 3, p. 86-98, 2001.

VON GLASERSFELD, E. An exposition of constructivism: why some like it radical. Disponível em: < http://www.oikos.org/constructivism.htm>. Acesso em: 11 abr. 2006. A construção do conhecimento. In: SCHNITMAN, D. F. (Org.). Novos paradigmas, cultura e subjetividade. Porto Alegre: Artes Médicas, 1996. p. 75-92. 